\title{
Numerical Techniques for Unsteady Nonlinear Burgers Equation Based on Backward Differentiation Formulas
}

https://doi.org/10.1515/nleng-2017-0068

Received March 7, 2017; revised October 22, 2017; accepted December 9, 2017.

\begin{abstract}
We introduce new numerical techniques for solving nonlinear unsteady Burgers equation. The numerical technique involves discretization of all variables except the time variable which converts nonlinear PDE into nonlinear ODE system. Stability of the nonlinear system is verified using Lyapunov's stability criteria. Implicit stiff solvers backward differentiation formula of order one, two and three are used to solve the nonlinear ODE system. Four test problems are included to show the applicability of introduced numerical techniques. Numerical solutions so obtained are compared with solutions of existing schemes in literature. The proposed numerical schemes are found to be simple, accurate, fast, practical and superior to some existing methods.
\end{abstract}

Keywords: Burgers equation; Method of lines; Backward Differentiation Formula; Stability

\section{Introduction}

Consider the nonlinear unsteady Burgers equation

$$
u_{t}+u u_{x}=v u_{x x}, x \in[a, b] \text { and } t \in[0, T]
$$

with initial condition $u(x, 0)=f(x), a \leq x \leq b$, and boundary conditions $u(a, t)=0, u(b, t)=0,0 \leq t \leq T$.

Here $v>0$, is the viscosity parameter and $f(x)$ is given smooth function. Burgers proposed this equation as a mathematical model of turbulence. It is the simplified form of Navier-Stoke's equation. It has got application in various fields like gas dynamics [34], traffic flow [18],

Vijitha Mukundan, Department of Mathematics, National Institute of Technology, Calicut 673601, India, E-mail: vijithamukundan29@gmail.com

Ashish Awasthi, Department of Mathematics, National Institute of Technology, Calicut 673601, India, E-mail: aawasthi@nitc.ac.in shock theory [35], cosmology [38] etc. This equation has a time dependent term, convection term and diffusion term and can be used to test several numerical algorithms for Navier-Stoke's equation . Hence, mathematicians have shown much interest in finding its numerical as well as analytical solution. In 1915, Bateman [4] introduced this equation and gave steady state solution for the problem. Later on, in 1948, J. M. Burgers, a dutch physicist proposed this equation as a mathematical model for turbulence [6, 7] and due to his vast contribution the equation is named after him. Among the various numerical methods finite difference scheme draws more attention due to its simplicity, accuracy and wide applicability. Kadalbajoo and Awasthi [16] used Crank-Nicolson scheme effectively to the nonlinear Burgers equation using Cole-Hopf transformation. Among others numerical methods based on finite difference are given in $[2,3,5,9,17,20,22,23,33$, 41], while other methods include finite element method [32, 36, 37], Petro-Galerkin method [12], local-RBF meshless method [13], B-spline finite element method [14, 21, 24], and automatic differentiation method [1]. Recently, lattice Boltzmann method [11], multi-quadric quasi-interpolation [10] and meshless method [40] have been used to solve the nonlinear Burgers equation. A comparison of MOL to finite difference technique is presented in [19]. M. M Rashidi et al. [30] employed homotopy perturbation method for solving generalized Burger and Burger-Fisher equations, while in [31] homotopy analysis method is used to solve Burger and regularized long wave equations. In 2015, V. Mukundan and A. Awasthi [27] proposed efficient numerical techniques to solve Burgers equation which is based on finite difference schemes. They have used Cole-Hopf transformation to reduce Burgers equation to diffusion equation and solved by backward differentiation formulas. On the other hand in [28] authors used fourth order three stage Runge-Kutta method for solving the system of ODEs. In this paper, nonlinear time dependent Burgers equation is treated directly by Method of lines (MOL)technique without using any transformation. In Method of lines only the derivatives along X-direction are approximated by finite differences and the procedure is explained in Section 2. This technique reduces the nonlinear PDE to nonlinear 
system of ODE's. In Section 3 stability of this nonlinear system is verified by Lyapunov's indirect Method. Using Taylor series expansion the nonlinear system is linearized and then solved by Backward Differentiation Formulas which has been explained in Section 4. Four test problems have been solved, numerical outcomes have been discussed, two and three dimensional figures have been presented and comparison with other numerical schemes are given in Section 5. Conclusions are presented in Section 6.

\section{Proposed Scheme}

In this paper, we have proposed some schemes for efficiently dealing with the time dependent nonlinear Burgers equation. First we apply method of lines technique by discretizing the X-direction. For this we divide the spatial direction into $N+1$ equally spaced points with space interval $h=(b-a) / N$. Spatial derivatives are approximated using central difference scheme as given below.

$$
\frac{\partial u}{\partial x}\left(x_{i}, t\right)=\frac{u_{i+1}(t)-u_{i-1}(t)}{2 h}, i=1,2, \ldots N-1 .
$$

$$
\frac{\partial^{2} u}{\partial x^{2}}\left(x_{i}, t\right)=\frac{u_{i+1}(t)-2 u_{i}(t)+u_{i-1}(t)}{h^{2}}, i=1,2, \ldots N-1 .
$$

Applying the boundary conditions $u_{0}(t)=0, u_{N}(t)=0$ and substituting in Eq. (1.1), we get

$$
\begin{aligned}
\frac{d u_{i}(t)}{d t}= & \frac{v}{h^{2}}\left(u_{i+1}(t)-2 u_{i}(t)+u_{i-1}(t)\right) \\
& -\frac{u_{i}(t)}{2 h}\left(u_{i+1}(t)-u_{i-1}(t)\right) \\
u_{i}(0) & =u_{0}\left(x_{i}\right), i=1,2, \ldots N-1
\end{aligned}
$$

where, $u_{i}(t)$ is approximation of $u\left(x_{i}, t\right)$.

ODE system arising from the substituition of $\mathbf{U}(t)=$ $\left[u_{1}(t), \ldots . u_{N-1}(t)\right]^{\top}$ in Eq. (2.2) is given by

$$
\begin{gathered}
\frac{d \mathbf{U}}{d t}=\mathbf{F}(\mathbf{U}, \mathbf{t}), \\
\mathbf{U}(0)=\mathbf{U}_{\mathbf{0}},
\end{gathered}
$$

where, $\mathbf{F}$ is a nonlinear function of $\mathbf{U}$ with elements $f_{i}$ which are defined as:

$$
\begin{aligned}
f_{i}\left(u_{1}, u_{2}, \ldots, u_{N-1}, t\right) & =u_{i+1}\left(\lambda_{1}-\lambda_{2} u_{i}\right)-u_{i}\left(2 \lambda_{1}\right. \\
\left.-\lambda_{2} u_{i-1}\right)+\lambda_{1} u_{i-1}, i & =1,2, \ldots N-1
\end{aligned}
$$

$$
\lambda_{1}=\frac{v}{(h)^{2}}, \lambda_{2}=\frac{1}{(2 h)}
$$

We will analyze the nonlinear system of ordinary differential equations (2.4) for existence, uniqueness of solution and its stability.

\section{Theorem I}

Let $\mathbf{F}(\mathbf{U}, t)$ be a continuous function. Then the initial value problem (IVP)

$$
\frac{d \mathbf{U}}{d t}=\mathbf{F}(\mathbf{U}, t), \mathbf{U}\left(t_{0}\right)=a
$$

admits a solution $\mathbf{U}=f(t)$ in $\left|\left(t-t_{0}\right)\right|<\delta$ for some $\delta>0$.

Proof. Since the functions defined above

$$
\begin{aligned}
& f_{i}\left(u_{1}, u_{2}, \ldots, u_{N-1}, t\right)=u_{i+1}\left(\lambda_{1}-\lambda_{2} u_{i}\right)-u_{i}\left(2 \lambda_{1}-\lambda_{2} u_{i-1}\right) \\
& +\lambda_{1} u_{i-1}, i=1,2, \ldots N-1
\end{aligned}
$$

are clearly continuous we can assure that solution exist for this IVP.

\section{Theorem II}

Let $\mathbf{C}^{\mathbf{1}}$ denote the class of all differentiable functions whose first derivative is continuous.

If $\mathbf{F}(\mathbf{U}, t) \in \mathbf{C}^{\mathbf{1}}$ then there exist one and only one solution to the IVP.

\section{Proof}

The partial derivatives of the functions given in eq (2.5) are

$$
\begin{gathered}
\frac{\partial f_{i}}{\partial u_{i}}=-2 \lambda_{1}-\lambda_{2} u_{i+1}+\lambda_{2} u_{i-1}, i=1,2, \ldots N-1 \\
\frac{\partial f_{i}}{\partial u_{i+1}}=\lambda_{1}-\lambda_{2} u_{i}, i=1,2, \ldots N-1 \\
\frac{\partial f_{i}}{\partial u_{i-1}}=\lambda_{1}+\lambda_{2} u_{i}, i=1,2, \ldots N-1 \\
\frac{\partial f_{i}}{\partial u_{j}}=0, i=1,2, \ldots N-1, j \neq i-1, i, i+1
\end{gathered}
$$

All the partial derivatives of the function exist and are continuous everywhere in the domain, thus $\mathbf{F}(\mathbf{U}, t) \in \mathbf{C}^{\mathbf{1}}$. Hence the IVP has a unique solution.

Stability of the nonlinear system will be investigated in the next section. 


\section{Stability Analysis}

One of the most important mathematical tool for analysis of stability of nonlinear system is Lyapunov's stability theory . It allows to test the stability of a nonlinear autonomous system by finding the eigenvalues of the Jacobian matrix at the equilibrium point.

Consider the nonlinear system Eq. (2.4). Since the system is autonomous we have

$$
\begin{gathered}
\frac{d \mathbf{U}}{d t}=\mathbf{F}(\mathbf{U}), \\
\mathbf{U}(0)=\mathbf{U}_{\mathbf{0}}
\end{gathered}
$$

where $\mathbf{F}$ is a nonlinear function of $\mathbf{U}$ with elements $f_{i}$ defined as:

$$
\begin{aligned}
& f_{i}\left(u_{1}, u_{2}, \ldots, u_{N-1}, t\right)=u_{i+1}\left(\lambda_{1}-\lambda_{2} u_{i}\right)-u_{i}\left(2 \lambda_{1}-\lambda_{2} u_{i-1}\right) \\
& +\lambda_{1} u_{i-1}, i=1,2, \ldots N-1
\end{aligned}
$$

Expanding $\mathbf{F}$ as a Taylor series about the equilibrium point $\mathbf{U}^{\star}=0$, we have

$$
\begin{aligned}
\mathbf{F}(U) & \cong \mathbf{F}\left(U^{\star}\right)+\mathbf{F}^{\prime}\left(U^{\star}\right)\left(\mathbf{U}-\mathbf{U}^{\star}\right) \\
& \cong \mathbf{F}^{\prime}\left(U^{\star}\right) \mathbf{U}
\end{aligned}
$$

We will investigate the stability of the system Eq. (3.6) using Lyapunov's Indirect Method.

\subsection{Lyapunov's Indirect Method}

Let $x=0$ be an equilibrium point of $\dot{x}=f(x)$, where $f: D \longrightarrow R^{n}$ is a continuously differentiable and $D$ is a neighborhood of the origin. Let

$$
A=\left.\frac{\partial f}{\partial x}\right|_{x=0}
$$

Then

1. The origin is asymptotically stable if $\operatorname{Re}\left(\lambda_{i}\right)<0$ for all eigenvalues $\lambda_{i}$ of A

2. The origin is unstable if $\operatorname{Re}\left(\lambda_{i}\right)>0$ for some eigenvalues $\lambda_{i}$ of $\mathrm{A}$

For the nonlinear system Eq. (3.6) the Jacobian matrix is given by

$$
J_{F}^{(n)}=\left(\begin{array}{cccc}
\left(\frac{\partial f_{1}}{\partial u_{1}}\right)^{(n)} & \left(\frac{\partial f_{1}}{\partial u_{2}}\right)^{(n)} & \ldots & \left(\frac{\partial f_{1}}{\partial u_{N-1}}\right)^{(n)} \\
\vdots & & & \\
\left(\frac{\partial f_{N-1}}{\partial u_{1}}\right)^{(n)} & \left(\frac{\partial f_{N-1}}{\partial u_{2}}\right)^{(n)} & \ldots & \left(\frac{\partial f_{N-1}}{\partial u_{N-1}}\right)^{(n)}
\end{array}\right)
$$

Let matrix $A$ denote Jacobian matrix evaluated at the equilibrium point. Then $A$ is a tridiagonal matrix given by

$$
A=\left(\begin{array}{ccccc}
-2 \lambda_{1} & \lambda_{1} & & & \\
\lambda_{1} & -2 \lambda_{1} & \lambda_{1} & & \\
& \ddots & \ddots & \ddots & \\
& & \lambda_{1} & -2 \lambda_{1} & \lambda_{1} \\
& & & \lambda_{1} & -2 \lambda_{1}
\end{array}\right)
$$

Eigenvalues of this matrix are of the form

$$
-2 \lambda_{1}+2 \lambda_{1} \cos \left(\frac{s \pi}{n+1}\right), s=1,2, \ldots, n .
$$

Since, $-1<\cos \left(\frac{s \pi}{n+1}\right)<1 \Rightarrow 2 \lambda_{1} \cos \left(\frac{s \pi}{n+1}\right)<2 \lambda_{1}$.

We have $-2 \lambda_{1}+2 \lambda_{1} \cos \left(\frac{s \pi}{n+1}\right)<0$,

i.e all eigenvalues of the Jacobian matrix are in the open left half complex plane. Hence origin is asymptotically stable for the nonlinear system.

\section{Numerical Integration}

Divide the time interval into $M+1$ equally spaced points with time step $\Delta t=T / M$. For time integration we use backward differentiation formulas.

\subsection{Backward Differentiation Formula of order one (BDF-1)}

$$
\mathbf{U}^{\mathbf{n}+\mathbf{1}}=\mathbf{U}^{\mathbf{n}}+(\Delta t) \mathbf{F}\left(\mathbf{U}^{\mathbf{n}+\mathbf{1}}, \mathbf{t}^{\mathbf{n}+\mathbf{1}}\right), n=0,1, \ldots M-1
$$

$\mathbf{U}^{\mathbf{0}}$ is the initial condition and $\mathbf{U}^{(n)}=\left[u_{1}^{(n)}, \ldots . u_{N-1}^{(n)}\right]^{T}$.

Since the system (4.7) is nonlinear, we can linearize it by using Taylor series expansion about $\mathbf{U}^{(n)}$

$$
\mathbf{F}\left(\mathbf{U}^{(n+1)}\right)=\mathbf{F}\left(\mathbf{U}^{(n)}\right)+J_{F}^{(n)}\left(\mathbf{U}^{(n+1)}-\mathbf{U}^{(n)}\right)+O\left((\Delta t)^{2}\right),
$$

where $J_{F}^{(n)}$ is the Jacobian matrix at the $n^{\text {th }}$ time level.

Substituting Eq. (4.8) in Eq. (4.7) we get,

$$
\begin{gathered}
\mathbf{U}^{(n+1)}=\mathbf{U}^{(n)}+\Delta t\left[\mathbf{F}\left(\mathbf{U}^{(n)}\right)+J_{F}^{(n)}\left(\mathbf{U}^{(n+1)}-\mathbf{U}^{(n)}\right)\right] \\
\mathbf{U}^{(n+1)}=\mathbf{U}^{(n)}+\left(I-\Delta t J_{F}^{(n)}\right)^{-1} \Delta t\left[\mathbf{F}\left(\mathbf{U}^{(n)}\right)\right]
\end{gathered}
$$

\subsection{Backward Differentiation Formula of order two (BDF-2)}

$\mathbf{U}^{(n+1)}=\frac{4}{3} \mathbf{U}^{\mathbf{n}}-\frac{1}{3} \mathbf{U}^{\mathbf{n}-\mathbf{1}}+\frac{2}{3}(\Delta t) \mathbf{F}\left(\mathbf{U}^{\mathbf{n}+\mathbf{1}}, \mathbf{t}^{\mathbf{n}+\mathbf{1}}\right), \quad n=1,2, \ldots M-1$ 
$\mathbf{U}^{1}$ is attained from BDF-1. For linearisation we use Taylor series expansion

$$
\mathbf{F}\left(\mathbf{U}^{(n+1)}\right)=\mathbf{F}\left(\mathbf{U}^{(n)}\right)+J_{F}^{(n)}\left(\mathbf{U}^{(n+1)}-\mathbf{U}^{(n)}\right)+O\left((\Delta t)^{2}\right),
$$

where $J_{F}^{(n)}$ is the Jacobian matrix at the $n^{\text {th }}$ time level.

Substituting Eq. (4.11) in Eq. (4.10) we get,

$$
\begin{gathered}
\mathbf{U}^{(n+1)}=\frac{4}{3} \mathbf{U}^{(n)}-\frac{1}{3} \mathbf{U}^{(n-1)}+\frac{2 \Delta t\left[\mathbf{F}\left(\mathbf{U}^{(n)}\right)+J_{F}^{(n)}\left(\mathbf{U}^{(n+1)}-\mathbf{U}^{(n)}\right)\right]}{3} \\
\left(I-\frac{2 \Delta t}{3} J_{F}^{(n)}\right) \mathbf{U}^{(n+1)}=\left(\frac{4}{3} I-\frac{2 \Delta t}{3} J_{F}^{(n)}\right) \mathbf{U}^{(n)}+\frac{2 \Delta t \mathbf{F}\left(\mathbf{U}^{(n)}\right)}{3}-\frac{1}{3} \mathbf{U}^{(n-1)} \\
\mathbf{U}^{(n+1)}=\left(I-\frac{2 \Delta t}{3} J_{F}^{(n)}\right)^{-1}\left(\frac{4}{3} I-\frac{2 \Delta t}{3} J_{F}^{(n)}\right) \mathbf{U}^{(n)} \\
\quad+\left(I-\frac{2 \Delta t}{3} J_{F}^{(n)}\right)^{-1} \frac{2 \Delta t \mathbf{F}\left(\mathbf{U}^{(n)}\right)}{3}-\left(I-\frac{2 \Delta t}{3} J_{F}^{(n)}\right)^{-1} \frac{1}{3} \mathbf{U}^{(n-1)}
\end{gathered}
$$

Hence the above scheme is linearized. Now, we need only to solve linear algebraic equations Eq. (4.12) which take less computational time.

\subsection{Backward Differentiation Formula of order three (BDF-3)}

$$
\begin{aligned}
\mathbf{U}^{(n+1)} & =\frac{18}{11} \mathbf{U}^{\mathbf{n}}-\frac{9}{11} \mathbf{U}^{\mathbf{n}-\mathbf{1}}+\frac{2}{11} \mathbf{U}^{\mathbf{n}-\mathbf{2}}+\frac{6}{11}(\Delta t) \mathbf{F}\left(\mathbf{U}^{\mathbf{n}+\mathbf{1}}, \mathbf{t}^{\mathbf{n}+\mathbf{1}}\right), \\
n & =2, \ldots M-1
\end{aligned}
$$

$\mathbf{U}^{1}$ and $\mathbf{U}^{2}$ are attained from BDF-1. For linearisation we use Taylor series expansion

$$
\mathbf{F}\left(\mathbf{U}^{(n+1)}\right)=\mathbf{F}\left(\mathbf{U}^{(n)}\right)+J_{F}^{(n)}\left(\mathbf{U}^{(n+1)}-\mathbf{U}^{(n)}\right)+O\left((\Delta t)^{2}\right),
$$

where $J_{F}^{(n)}$ is the Jacobian matrix at the $n^{\text {th }}$ time level.

Substituting Eq. (4.14) in Eq. (4.13) we get,

$$
\begin{gathered}
\mathbf{U}^{(n+1)}=\frac{18}{11} \mathbf{U}^{(n)}-\frac{9}{11} \mathbf{U}^{(n-1)}+\frac{2}{11} \mathbf{U}^{(n-2)} \\
+\frac{6 \Delta t\left[\mathbf{F}\left(\mathbf{U}^{(n)}\right)+J_{F}^{(n)}\left(\mathbf{U}^{(n+1)}-\mathbf{U}^{(n)}\right)\right]}{11} \\
\left(I-\frac{6 \Delta t}{11} J_{F}^{(n)}\right) \mathbf{U}^{(n+1)}=\left(\frac{18}{11} I-\frac{6 \Delta t}{11} J_{F}^{(n)}\right) \mathbf{U}^{(n)}+\frac{6 \Delta t \mathbf{F}\left(\mathbf{U}^{(n)}\right)}{11} \\
-\frac{9}{11} \mathbf{U}^{(n-1)}+\frac{2}{11} \mathbf{U}^{(n-2)} \\
\mathbf{U}^{(n+1)}=\left(I-\frac{6 \Delta t}{11} J_{F}^{(n)}\right)^{-1}\left(\frac{18}{11} I-\frac{6 \Delta t}{11} J_{F}^{(n)}\right) \mathbf{U}^{(n)} \\
+\left(I-\frac{6 \Delta t}{11} J_{F}^{(n)}\right)^{-1} \frac{6 \Delta t \mathbf{F}\left(\mathbf{U}^{(n)}\right)}{11}-\left(I-\frac{6 \Delta t}{11} J_{F}^{(n)}\right)^{-1} \frac{9}{11} \mathbf{U}^{(n-1)} \\
+\left(I-\frac{6 \Delta t}{11} J_{F}^{(n)}\right)^{-1} \frac{2}{11} \mathbf{U}^{(n-2)}
\end{gathered}
$$

where, $J_{F}^{(n)}$ is the Jacobian matrix at the $n^{\text {th }}$ time level. Hence the above scheme is linearized. Again, we need only to solve linear algebraic equations which take less computation time.

\section{Numerical results and discussion}

Several test experiments were conducted to check the efficiency and adaptability of the proposed numerical schemes. A comparison is made between the computed solutions and the test problems whose exact solutions are known for different values of viscosity $v$ and at different values of final time. The numerical solutions are also compared with results given in the literature. All numerical calculations were performed using codes produced in MATLAB 8.0.

Example-1 Consider the Burgers Equation [8]

$$
u_{t}+u u_{x}=v u_{x x}, x \in[0,1] \text { and } t \in[0, T]
$$

with initial condition $u(x, 0)=\sin (\pi x), 0 \leq x \leq 1$, and the boundary conditions $u(0, t)=u(1, t)=0,0 \leq t \leq T$. The exact solution of the problem is

$$
u(x, t)=2 \pi v \frac{\sum_{n=1}^{\infty} C_{n} \exp \left(-n^{2} \pi^{2} v t\right) n \sin (n \pi x)}{C_{0}+\sum_{n=1}^{\infty} C_{n} \exp \left(-n^{2} \pi^{2} v t\right) \cos (n \pi x)},
$$

$C_{0}=\int_{0}^{1} \exp \left\{-\frac{1}{2 \pi v}[1-\cos (\pi x)]\right\} d x, \quad C_{n}=$ $2 \int_{0}^{1} \exp \left\{-\frac{1}{2 \pi v}[1-\cos (\pi x)]\right\} \cos (n \pi x) d x$.

The Burgers equation has been solved directly by first applying method of lines semi discretization technique followed by implicit solvers backward differentiation formulas of order one, two and three. In Table 1, numerical solutions obtained by proposed method followed by backward differentiation formulas are compared with the exact solutions for viscosity $v=0.1$ at different times $T=0.1,0.2,0.3$. It has been observed that numerical solutions obtained by BDF-2 and BDF-3 provides better accuracy than BDF-1. The experiment was repeated for different values of viscosity $v$ at different time levels $T$. Results are tabulated and presented in Tables 2-4 for viscosity $v=0.02,0.01,1$ at different time levels $T$. Numerical schemes implementing BDF-1 and BDF-2 are respectively discussed in our papers [29] and [26]. In Table 5, we have compared the proposed numerical schemes using implicit solvers BDF-2 and BDF-3 with other schemes available in literature. It has been observed that the proposed numerical schemes shows excellent agreement with exact solutions as compared to the schemes given in [21] and [32]. Numerical results obtained by proposed schemes are 
also comparable to those given in [17]. Discrete root mean square error norm $\left(L_{2}\right)$ and maximum error norm $\left(L_{\infty}\right)$ are computed for $v=0.05,0.0125$, at different time levels and presented in Table 6 .

Figure 1, shows comparison between numerical and exact solutions of example 1 for viscosity $v=1,0.1$ at different time levels $T$. It has been observed that numerical solutions using BDF-2 agrees exactly with exact solutions. Physical behavior of numerical solutions at different times $T$ in 3D and contour form for $v=0.0066$ has been presented in Figure 2.

Most of the numerical methods available in literature fails to capture physical behavior of the equation as viscosity tends to zero $(v \rightarrow 0)$. Figure 3 shows the proposed scheme is able to capture the physical behavior for $v=0.0001,0.00001$. Hence the proposed schemes overcome the drawback of several other numerical schemes given in the literature.

Table 1: Numerical solutions obtained by proposed schemes and the exact solutions for Example 1: $v=0.1, \Delta x=0.0125$ and $\Delta t=0.001$.

\begin{tabular}{cccccc}
\hline \multirow{2}{*}{$T$} & $x$ & \multicolumn{3}{c}{ Computed Solution } & \multirow{2}{*}{ Exact Solution } \\
\cline { 3 - 5 } & & BDF-1 & BDF-2 & BDF-3 & \\
\hline \multirow{3}{*}{0.1} & 0.25 & $5.3461 \mathrm{E}-01$ & $5.3427 \mathrm{E}-01$ & $5.3428 \mathrm{E}-01$ & $5.3414 \mathrm{E}-01$ \\
& 0.50 & $8.7741 \mathrm{E}-01$ & $8.7740 \mathrm{E}-01$ & $8.7740 \mathrm{E}-01$ & $8.7728 \mathrm{E}-01$ \\
& 0.75 & $7.6148 \mathrm{E}-01$ & $7.6183 \mathrm{E}-01$ & $7.6183 \mathrm{E}-01$ & $7.6180 \mathrm{E}-01$ \\
\hline \multirow{3}{*}{0.2} & 0.25 & $4.2982 \mathrm{E}-01$ & $4.2944 \mathrm{E}-01$ & $4.2945 \mathrm{E}-01$ & $4.2932 \mathrm{E}-01$ \\
& 0.50 & $7.5423 \mathrm{E}-01$ & $7.5403 \mathrm{E}-01$ & $7.5403 \mathrm{E}-01$ & $7.5381 \mathrm{E}-01$ \\
& 0.75 & $7.4884 \mathrm{E}-01$ & $7.4928 \mathrm{E}-01$ & $7.4928 \mathrm{E}-01$ & $7.4914 \mathrm{E}-01$ \\
\hline \multirow{3}{*}{0.3} & 0.25 & $3.5969 \mathrm{E}-01$ & $3.5934 \mathrm{E}-01$ & $3.5935 \mathrm{E}-01$ & $3.5923 \mathrm{E}-01$ \\
& 0.50 & $6.5227 \mathrm{E}-01$ & $6.5197 \mathrm{E}-01$ & $6.5197 \mathrm{E}-01$ & $6.5173 \mathrm{E}-01$ \\
& 0.75 & $6.9505 \mathrm{E}-01$ & $6.9534 \mathrm{E}-01$ & $6.9533 \mathrm{E}-01$ & $6.9508 \mathrm{E}-01$ \\
\hline
\end{tabular}

Table 2: Numerical solutions obtained by proposed schemes and the exact solutions for Example 1: $v=0.02, \Delta x=0.0125$ and $\Delta t=0.001$.

\begin{tabular}{cccccc}
\hline \multirow{2}{*}{$T$} & $x$ & \multicolumn{3}{c}{ Computed Solution } & \multirow{2}{*}{ Exact Solution } \\
\cline { 3 - 5 } & & BDF-1 & BDF-2 & BDF-3 & \\
\hline \multirow{3}{*}{0.1} & 0.25 & $5.6316 \mathrm{E}-01$ & $5.6293 \mathrm{E}-01$ & $5.6293 \mathrm{E}-01$ & $5.6277 \mathrm{E}-01$ \\
& 0.50 & $9.3943 \mathrm{E}-01$ & $9.3965 \mathrm{E}-01$ & $9.3964 \mathrm{E}-01$ & $9.3954 \mathrm{E}-01$ \\
& 0.75 & $8.4823 \mathrm{E}-01$ & $8.4847 \mathrm{E}-01$ & $8.4847 \mathrm{E}-01$ & $8.4841 \mathrm{E}-01$ \\
\hline \multirow{4}{*}{0.2} & 0.25 & $4.6318 \mathrm{E}-01$ & $4.6285 \mathrm{E}-01$ & $4.6285 \mathrm{E}-01$ & $4.6266 \mathrm{E}-01$ \\
& 0.50 & $8.3868 \mathrm{E}-01$ & $8.3868 \mathrm{E}-01$ & $8.3868 \mathrm{E}-01$ & $8.3844 \mathrm{E}-01$ \\
& 0.75 & $9.3655 \mathrm{E}-01$ & $9.3739 \mathrm{E}-01$ & $9.3739 \mathrm{E}-01$ & $9.3721 \mathrm{E}-01$ \\
\hline \multirow{3}{*}{0.3} & 0.25 & $3.9201 \mathrm{E}-01$ & $3.9167 \mathrm{E}-01$ & $3.9167 \mathrm{E}-01$ & $3.9150 \mathrm{E}-01$ \\
& 0.50 & $7.3916 \mathrm{E}-01$ & $7.3894 \mathrm{E}-01$ & $7.3894 \mathrm{E}-01$ & $7.3864 \mathrm{E}-01$ \\
& 0.75 & $9.3956 \mathrm{E}-01$ & $9.4041 \mathrm{E}-01$ & $9.4040 \mathrm{E}-01$ & $9.4007 \mathrm{E}-01$ \\
\hline
\end{tabular}

Table 3: Numerical solutions obtained by proposed schemes and the exact solutions for Example 1: $v=0.01, \Delta x=0.0125$ and $\Delta t=0.0001$.

\begin{tabular}{cccccc}
\hline \multirow{2}{*}{$T$} & $x$ & \multicolumn{3}{c}{ Computed Solution } & \multirow{2}{*}{ Exact Solution } \\
\cline { 3 - 5 } & & BDF-1 & BDF-2 & BDF-3 & \\
\hline \multirow{3}{*}{1} & 0.25 & $1.8823 \mathrm{E}-01$ & $1.8821 \mathrm{E}-01$ & $1.8821 \mathrm{E}-01$ & $1.8819 \mathrm{E}-01$ \\
& 0.50 & $3.7449 \mathrm{E}-01$ & $3.7445 \mathrm{E}-01$ & $3.7445 \mathrm{E}-01$ & $3.7442 \mathrm{E}-01$ \\
& 0.75 & $5.5615 \mathrm{E}-01$ & $5.5610 \mathrm{E}-01$ & $5.5610 \mathrm{E}-01$ & $5.5605 \mathrm{E}-01$ \\
\hline \multirow{2}{*}{2} & 0.25 & $1.0739 \mathrm{E}-01$ & $1.0739 \mathrm{E}-01$ & $1.0739 \mathrm{E}-01$ & $1.0738 \mathrm{E}-01$ \\
& 0.50 & $2.1459 \mathrm{E}-01$ & $2.1457 \mathrm{E}-01$ & $2.1457 \mathrm{E}-01$ & $2.1456 \mathrm{E}-01$ \\
& 0.75 & $3.2133 \mathrm{E}-01$ & $3.2131 \mathrm{E}-01$ & $3.2131 \mathrm{E}-01$ & $3.2128 \mathrm{E}-01$ \\
\hline & 0.25 & $7.5122 \mathrm{E}-02$ & $7.5117 \mathrm{E}-02$ & $7.5117 \mathrm{E}-02$ & $7.5114 \mathrm{E}-02$ \\
3 & 0.50 & $1.5020 \mathrm{E}-01$ & $1.5018 \mathrm{E}-01$ & $1.5018 \mathrm{E}-01$ & $1.5018 \mathrm{E}-01$ \\
& 0.75 & $2.2487 \mathrm{E}-01$ & $2.2485 \mathrm{E}-01$ & $2.2485 \mathrm{E}-01$ & $2.2481 \mathrm{E}-01$ \\
\hline
\end{tabular}

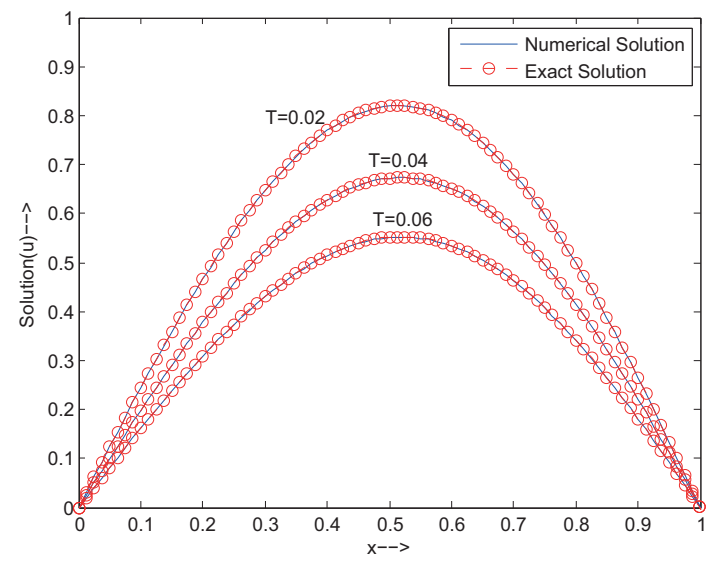

(a)

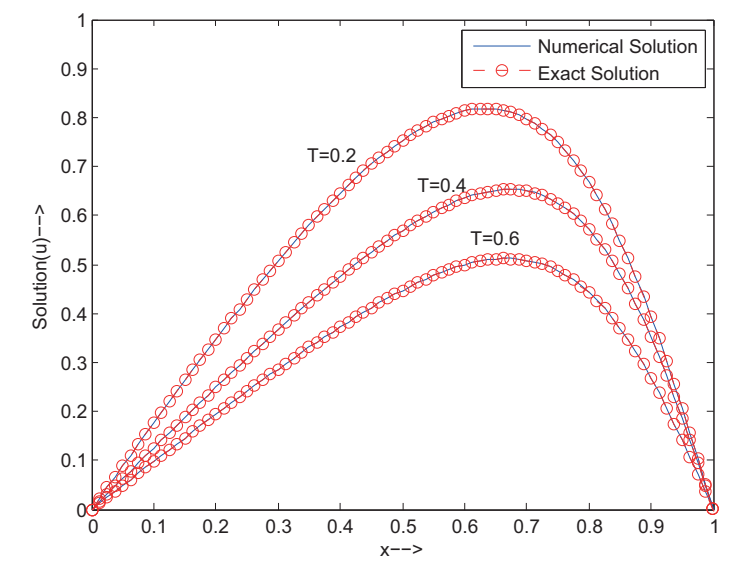

(b)

Fig. 1: Example 1: Numerical solutions at different times for $\Delta x=$ 0.0125 and different values of $v$ and $\Delta t$, (a) $v=1, \Delta t=0.0001$ (b) $v=0.1, \Delta t=0.001$. 
Table 4: Numerical solutions obtained by proposed schemes and the exact solutions for Example 1: $v=1, \Delta x=0.0125$ and $\Delta t=$ 0.0001 .

\begin{tabular}{cccccc}
\hline \multirow{2}{*}{$T$} & \multirow{2}{*}{$x$} & \multicolumn{3}{c}{ Computed Solution } & \multirow{2}{*}{ Exact Solution } \\
\cline { 3 - 5 } & & BDF-1 & BDF-2 & BDF-3 & \\
\hline \multirow{3}{*}{0.01} & 0.25 & $6.2911 \mathrm{E}-01$ & $6.2905 \mathrm{E}-01$ & $6.2905 \mathrm{E}-01$ & $6.2904 \mathrm{E}-01$ \\
& 0.50 & $9.0577 \mathrm{E}-01$ & $9.0573 \mathrm{E}-01$ & $9.0573 \mathrm{E}-01$ & $9.0571 \mathrm{E}-01$ \\
& 0.75 & $6.5244 \mathrm{E}-01$ & $6.5244 \mathrm{E}-01$ & $6.5244 \mathrm{E}-01$ & $6.5244 \mathrm{E}-01$ \\
\hline \multirow{3}{*}{0.02} & 0.25 & $5.6322 \mathrm{E}-01$ & $5.6313 \mathrm{E}-01$ & $5.6313 \mathrm{E}-01$ & $5.6312 \mathrm{E}-01$ \\
& 0.50 & $8.2020 \mathrm{E}-01$ & $8.2012 \mathrm{E}-01$ & $8.2012 \mathrm{E}-01$ & $8.2010 \mathrm{E}-01$ \\
& 0.75 & $5.9810 \mathrm{E}-01$ & $5.9808 \mathrm{E}-01$ & $5.9808 \mathrm{E}-01$ & $5.9807 \mathrm{E}-01$ \\
\hline \multirow{3}{*}{0.03} & 0.25 & $5.0650 \mathrm{E}-01$ & $5.0639 \mathrm{E}-01$ & $5.0639 \mathrm{E}-01$ & $5.0639 \mathrm{E}-01$ \\
& 0.50 & $7.4273 \mathrm{E}-01$ & $7.4262 \mathrm{E}-01$ & $7.4262 \mathrm{E}-01$ & $7.4259 \mathrm{E}-01$ \\
& 0.75 & $5.4572 \mathrm{E}-01$ & $5.4568 \mathrm{E}-01$ & $5.4568 \mathrm{E}-01$ & $5.4567 \mathrm{E}-01$ \\
\hline
\end{tabular}

(a)

Table 5: Comparison with different numerical methods and exact solution of Example 1 for $v=0.01$.

\begin{tabular}{cccccccc}
\hline$x$ & Time & {$[21]$} & {$[32]$} & {$[17]$} & BDF-2 & BDF-3 & Exact Solution \\
& & $\Delta t=0.0001$ & $\Delta t=0.001$ & $\Delta t=0.01$ & $\Delta t=0.001$ & $\Delta t=0.001$ & \\
\hline \multirow{4}{*}{0.25} & 0.4 & 0.34819 & 0.34244 & 0.34229 & 0.34207 & 0.34208 & 0.34191 \\
& 0.6 & 0.27536 & 0.26905 & 0.26902 & 0.26908 & 0.26908 & 0.26896 \\
& 0.8 & 0.22752 & 0.22145 & $\ldots \ldots \ldots$ & 0.22157 & 0.22157 & 0.22148 \\
& 1.0 & 0.19375 & 0.18813 & 0.18817 & 0.18826 & 0.18826 & 0.18819 \\
& 3.0 & 0.07754 & 0.07509 & 0.07511 & 0.07513 & 0.07513 & 0.07511 \\
\hline \multirow{4}{*}{0.50} & 0.4 & 0.66543 & 0.67152 & 0.66797 & 0.66103 & 0.66103 & 0.66071 \\
& 0.6 & 0.53525 & 0.53406 & 0.53211 & 0.52969 & 0.52969 & 0.52942 \\
& 0.8 & 0.44256 & 0.44143 & $\ldots \ldots \ldots$ & 0.43936 & 0.43936 & 0.43914 \\
& 1.0 & 0.38047 & 0.37568 & 0.37500 & 0.37459 & 0.37460 & 0.37442 \\
& 3.0 & 0.15362 & 0.15020 & 0.15018 & 0.15022 & 0.15022 & 0.15018 \\
\hline \multirow{4}{*}{0.75} & 0.4 & 0.91201 & 0.94675 & 0.93680 & 0.91064 & 0.91063 & 0.91026 \\
& 0.6 & 0.77132 & 0.78474 & 0.77724 & 0.76761 & 0.76761 & 0.76724 \\
& 0.8 & 0.65254 & 0.65659 & $\ldots \ldots .$. & 0.64772 & 0.64772 & 0.64740 \\
& 1.0 & 0.56157 & 0.56135 & 0.55833 & 0.55632 & 0.55632 & 0.55605 \\
& 3.0 & 0.22874 & 0.22502 & 0.22485 & 0.22491 & 0.22491 & 0.22481 \\
\hline
\end{tabular}

Table 6: Comparison of Errors in $L_{2}$ norm and $L_{\infty}$ norm with $\Delta t=$ 0.0001 for different values of $v$, corresponding to Example 1 .

\begin{tabular}{ccccc}
\hline \multirow{2}{*}{$T$} & \multicolumn{2}{c}{$v=0.05$} & \multicolumn{2}{c}{$v=0.0125$} \\
\cline { 2 - 5 } & $L_{2}$ & $L_{\infty}$ & $L_{2}$ & $L_{\infty}$ \\
\hline 0.01 & $4.27 \mathrm{E}-06$ & $1.84 \mathrm{E}-05$ & $4.37 \mathrm{E}-06$ & $1.38 \mathrm{E}-05$ \\
0.1 & $2.99 \mathrm{E}-05$ & $4.83 \mathrm{E}-05$ & $3.18 \mathrm{E}-05$ & $4.97 \mathrm{E}-05$ \\
0.15 & $1.19 \mathrm{E}-04$ & $1.86 \mathrm{E}-04$ & $1.37 \mathrm{E}-04$ & $2.27 \mathrm{E}-04$ \\
0.2 & $7.63 \mathrm{E}-05$ & $1.26 \mathrm{E}-04$ & $9.71 \mathrm{E}-05$ & $1.87 \mathrm{E}-04$ \\
0.25 & $1.21 \mathrm{E}-04$ & $2.32 \mathrm{E}-04$ & $1.99 \mathrm{E}-04$ & $5.17 \mathrm{E}-04$ \\
\hline
\end{tabular}

Example-2 Next, we consider the Burgers equation [8]

$$
u_{t}+u u_{x}=v u_{x x}, x \in[0,1] \text { and } t \in[0, T]
$$

with initial condition $u(x, 0)=4 x(1-x), 0 \leq x \leq 1$, and the following boundary conditions $u(0, t)=0=u(1, t), 0 \leq$ $t \leq T$.

The exact solution of the problem is

$$
u(x, t)=2 \pi v \frac{\sum_{n=1}^{\infty} D_{n} \exp \left(-n^{2} \pi^{2} v t\right) n \sin (n \pi x)}{D_{0}+\sum_{n=1}^{\infty} D_{n} \exp \left(-n^{2} \pi^{2} v t\right) \cos (n \pi x)}
$$
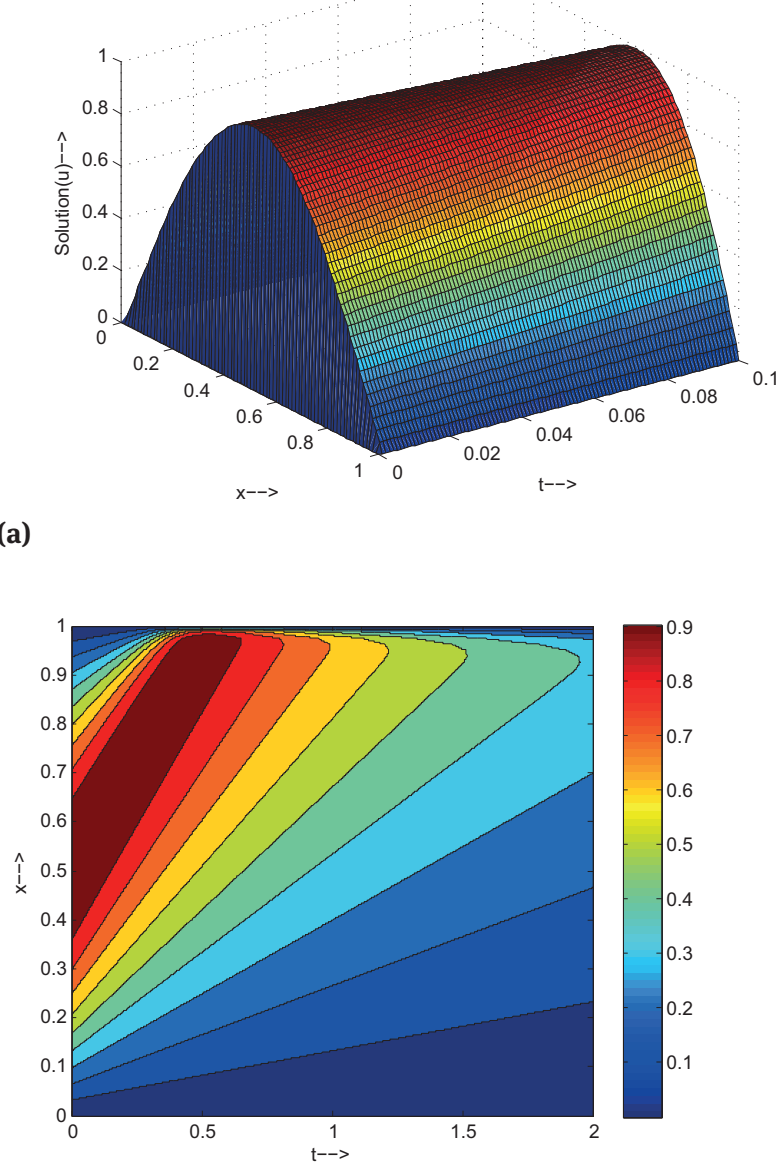

(b)

Fig. 2: Example 1: Physical behavior of numerical solutions at different times in 3D and contour for $\Delta x=0.0125, v=0.0066$, $\Delta t=0.001$ (a) $T=0.1$ (b) $T=2$.

where the Fourier coefficients $D_{0}$ and $D_{n}$ are the following $D_{0}=\int_{0}^{1} \exp \left\{-\frac{R_{e}}{3}\left[x^{2}(3-2 x)\right]\right\} d x, D_{n}=\int_{0}^{1} \exp \left\{-\frac{R_{e}}{3}\left[x^{2}(3-\right.\right.$ $2 x)]\} \cos (n \pi x) d x$.

For example 2, we have compared solutions obtained by proposed methods with exact solutions for viscosity $v=0.05$ at different final time levels $T=0.1,0.2,0.3$. The values are tabulated and presented in Table 7 . We have repeated the experiment with $v=0.0125$ at time levels $T=1,2,3$ and presented in Table 8. It has been observed that numerical solutions agrees with the exact solution. Moreover, numerical schemes using BDF-2 and BDF3 provide more accurate solutions as compared to BDF-1. To validate the accuracy of proposed numerical schemes, we have compared it with existing numerical schemes [15], [21] and [17] for viscosity $v=0.01$. Table 9 , shows that the proposed numerical schemes are comparable with the 


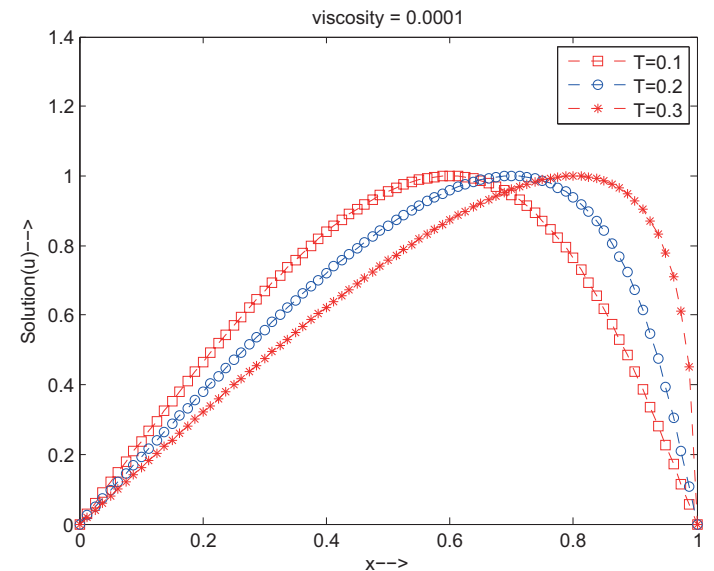

(a)

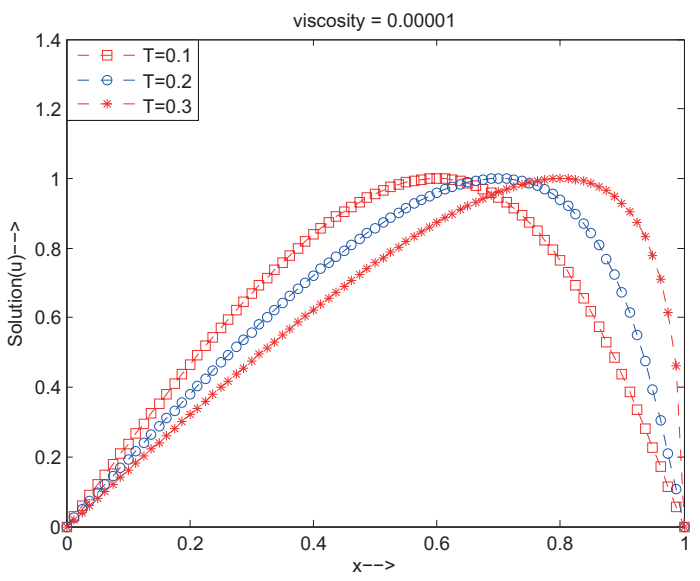

(b)

Fig. 3: Example 1: Physical behavior of numerical solutions at different times with $\Delta x=0.0125$ and $\Delta t=0.001$. (a) $v=0.0001$ (b) $v=0.00001$.

scheme given in [15] and it is better than the schemes given in [21] and [17]. Error norms $\left(L_{2}\right)$ and $\left(L_{\infty}\right)$ corresponding to example 2 are tabulated for $v=0.1,0.02$ in Table 10 .

Figure 4, shows that numerical solutions for test problem 2 agrees exactly with analytic solutions at each nodal points for viscosity $v=0.02,0.01$. The physical behavior of computed solutions is depicted in Figure 5 through contour and surface plots for viscosity $v=0.05$ and at different time levels $T$. Figure 6 shows the proposed scheme is able to capture the physical behavior for $v=0.0001,0.00001$.

Example-3 We also consider Burgers equation [39]

$$
u_{t}+u u_{x}=v u_{x x}, x \in[0,1] \text { and } t \in[0, T]
$$

with boundary conditions

$$
u(0, t)=0=u(1, t), \quad 0 \leq t \leq T
$$

Table 7: Numerical solutions obtained by proposed schemes and the exact solutions for Example 2: $v=0.05, \Delta x=0.0125$ and $\Delta t=0.0001$.

\begin{tabular}{cccccc}
\hline \multirow{2}{*}{$T$} & \multirow{2}{*}{$x$} & \multicolumn{3}{c}{ Computed Solution } & \multirow{2}{*}{ Exact Solution } \\
\cline { 3 - 5 } & & BDF-1 & BDF-2 & BDF-3 & \\
\hline \multirow{4}{*}{0.1} & 0.25 & $5.8696 \mathrm{E}-01$ & $5.8693 \mathrm{E}-01$ & $5.8693 \mathrm{E}-01$ & $5.8690 \mathrm{E}-01$ \\
& 0.50 & $9.2821 \mathrm{E}-01$ & $9.2823 \mathrm{E}-01$ & $9.2823 \mathrm{E}-01$ & $9.2821 \mathrm{E}-01$ \\
& 0.75 & $8.4401 \mathrm{E}-01$ & $8.4404 \mathrm{E}-01$ & $8.4404 \mathrm{E}-01$ & $8.4400 \mathrm{E}-01$ \\
\hline \multirow{4}{*}{0.2} & 0.25 & $4.7481 \mathrm{E}-01$ & $4.7477 \mathrm{E}-01$ & $4.7477 \mathrm{E}-01$ & $4.7473 \mathrm{E}-01$ \\
& 0.50 & $8.2664 \mathrm{E}-01$ & $8.2664 \mathrm{E}-01$ & $8.2664 \mathrm{E}-01$ & $8.2659 \mathrm{E}-01$ \\
& 0.75 & $8.8488 \mathrm{E}-01$ & $8.8493 \mathrm{E}-01$ & $8.8493 \mathrm{E}-01$ & $8.8479 \mathrm{E}-01$ \\
\hline \multirow{3}{*}{0.3} & 0.25 & $3.9750 \mathrm{E}-01$ & $3.9746 \mathrm{E}-01$ & $3.9746 \mathrm{E}-01$ & $3.9736 \mathrm{E}-01$ \\
& 0.50 & $7.2861 \mathrm{E}-01$ & $7.2859 \mathrm{E}-01$ & $7.2859 \mathrm{E}-01$ & $7.2843 \mathrm{E}-01$ \\
& 0.75 & $8.7081 \mathrm{E}-01$ & $8.7087 \mathrm{E}-01$ & $8.7087 \mathrm{E}-01$ & $8.7058 \mathrm{E}-01$ \\
\hline
\end{tabular}

Table 8: Numerical solutions obtained by proposed schemes and the exact solutions for Example 2: $v=0.0125, \Delta x=0.0125$ and $\Delta t=0.0001$.

\begin{tabular}{cccccc}
\hline$T$ & \multirow{2}{*}{$x$} & \multicolumn{3}{c}{ Computed Solution } & \multirow{2}{*}{ Exact Solution } \\
\cline { 3 - 5 } & & BDF-1 & BDF-2 & BDF-3 & \\
\hline \multirow{3}{*}{1} & 0.25 & $1.9410 \mathrm{E}-01$ & $1.9408 \mathrm{E}-01$ & $1.9409 \mathrm{E}-01$ & $1.9406 \mathrm{E}-01$ \\
& 0.50 & $3.8460 \mathrm{E}-01$ & $3.8456 \mathrm{E}-01$ & $3.8459 \mathrm{E}-01$ & $3.8453 \mathrm{E}-01$ \\
& 0.75 & $5.6774 \mathrm{E}-01$ & $5.6770 \mathrm{E}-01$ & $5.6774 \mathrm{E}-01$ & $5.6766 \mathrm{E}-01$ \\
\hline \multirow{3}{*}{2} & 0.25 & $1.0927 \mathrm{E}-01$ & $1.0926 \mathrm{E}-01$ & $1.0927 \mathrm{E}-01$ & $1.0926 \mathrm{E}-01$ \\
& 0.50 & $2.1818 \mathrm{E}-01$ & $2.1816 \mathrm{E}-01$ & $2.1817 \mathrm{E}-01$ & $2.1815 \mathrm{E}-01$ \\
& 0.75 & $3.2622 \mathrm{E}-01$ & $3.2619 \mathrm{E}-01$ & $3.2620 \mathrm{E}-01$ & $3.2615 \mathrm{E}-01$ \\
\hline & 0.25 & $7.6028 \mathrm{E}-02$ & $7.6023 \mathrm{E}-02$ & $7.6025 \mathrm{E}-02$ & $7.6020 \mathrm{E}-02$ \\
3 & 0.50 & $1.5197 \mathrm{E}-01$ & $1.5196 \mathrm{E}-01$ & $1.5196 \mathrm{E}-01$ & $1.5195 \mathrm{E}-01$ \\
& 0.75 & $2.2640 \mathrm{E}-01$ & $2.2639 \mathrm{E}-01$ & $2.2640 \mathrm{E}-01$ & $2.2631 \mathrm{E}-01$ \\
\hline
\end{tabular}

Table 9: Comparison with different numerical methods and exact solution of example 2 for $v=0.01$.

\begin{tabular}{cccccccc}
\hline$x$ & Time & {$[21]$} & {$[17]$} & {$[15]$} & BDF-2 & BDF-3 & Exact Solution \\
& & $\Delta t=0.0001$ & $\Delta t=0.01$ & $\Delta t=0.001$ & $\Delta t=0.001$ & $\Delta t=0.001$ & \\
\hline \multirow{3}{*}{0.25} & 0.4 & 0.36911 & 0.36273 & 0.36217 & 0.36244 & 0.36245 & 0.36226 \\
& 0.6 & 0.28905 & 0.28212 & 0.28197 & 0.28217 & 0.28217 & 0.28204 \\
& 0.8 & 0.23703 & $\ldots$ & 0.23040 & 0.23055 & 0.23055 & 0.23045 \\
& 1.0 & 0.20069 & 0.19467 & 0.19465 & 0.19477 & 0.19477 & 0.19469 \\
& 3.0 & 0.07865 & 0.07613 & 0.07613 & 0.07615 & 0.07615 & 0.07613 \\
\hline \multirow{3}{*}{0.50} & 0.4 & 0.68818 & 0.69186 & 0.68357 & 0.68398 & 0.68398 & 0.68368 \\
& 0.6 & 0.55425 & 0.55125 & 0.54822 & 0.54859 & 0.54860 & 0.54832 \\
& 0.8 & 0.46011 & $\ldots$ & 0.45363 & 0.45394 & 0.45395 & 0.45371 \\
& 1.0 & 0.39206 & 0.38627 & 0.38561 & 0.38586 & 0.38586 & 0.38568 \\
& 3.0 & 0.15576 & 0.15218 & 0.15217 & 0.15222 & 0.15222 & 0.15218 \\
\hline \multirow{3}{*}{0.75} & 0.4 & 0.92194 & 0.94940 & 0.92050 & 0.92079 & 0.92078 & 0.92050 \\
& 0.6 & 0.78676 & 0.79399 & 0.78293 & 0.78333 & 0.78333 & 0.78299 \\
& 0.8 & 0.66777 & $\ldots$ & 0.66264 & 0.66303 & 0.66303 & 0.66272 \\
& 1.0 & 0.57491 & 0.57170 & 0.56924 & 0.56959 & 0.56959 & 0.56932 \\
& 3.0 & 0.23183 & 0.22778 & 0.22774 & 0.22784 & 0.22784 & 0.22774 \\
\hline
\end{tabular}

and initial condition

$$
u(x, 0)=\frac{2 v \pi \sin (\pi x)}{2+\cos (\pi x)}, \quad 0 \leq x \leq 1 .
$$

The exact solution for this problem is

$$
u(x, t)=\frac{2 v \pi \exp \left(-\pi^{2} v t\right) \sin (\pi x)}{2+\exp \left(-\pi^{2} v t\right) \cos (\pi x)}
$$


Table 10: Comparison of Errors in $L_{2}$ norm and $L_{\infty}$ norm with $\Delta t=$ 0.001 for different values of $v$, corresponding to Example 2 .

\begin{tabular}{ccccc}
\hline \multirow{2}{*}{$T$} & \multicolumn{2}{c}{$v=0.1$} & \multicolumn{2}{c}{$v=0.02$} \\
\cline { 2 - 5 } & $L_{2}$ & $L_{\infty}$ & $L_{2}$ & $L_{\infty}$ \\
\hline 0.01 & $9.83 \mathrm{E}-05$ & $5.44 \mathrm{E}-04$ & $3.88 \mathrm{E}-05$ & $2.90 \mathrm{E}-04$ \\
0.05 & $8.29 \mathrm{E}-05$ & $2.83 \mathrm{E}-04$ & $7.72 \mathrm{E}-05$ & $2.39 \mathrm{E}-04$ \\
0.1 & $9.53 \mathrm{E}-05$ & $1.79 \mathrm{E}-04$ & $1.37 \mathrm{E}-04$ & $2.92 \mathrm{E}-04$ \\
0.15 & $1.18 \mathrm{E}-04$ & $1.80 \mathrm{E}-04$ & $2.14 \mathrm{E}-04$ & $5.27 \mathrm{E}-04$ \\
0.2 & $1.43 \mathrm{E}-04$ & $1.99 \mathrm{E}-04$ & $3.22 \mathrm{E}-04$ & $8.93 \mathrm{E}-04$ \\
\hline
\end{tabular}

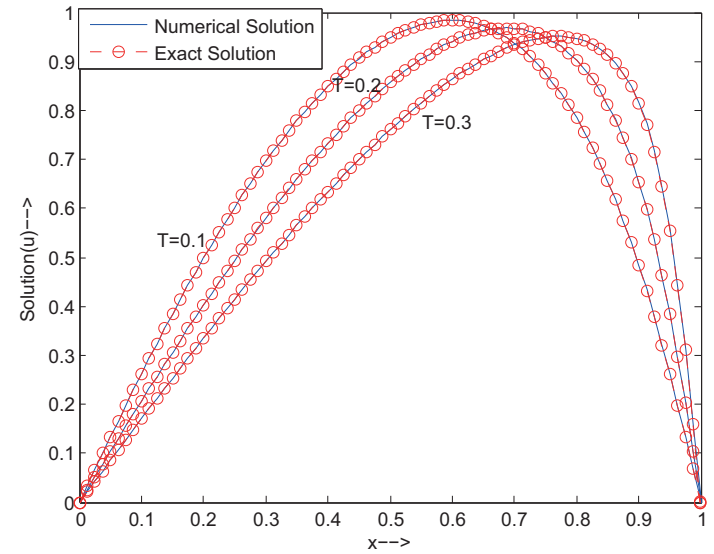

(a)

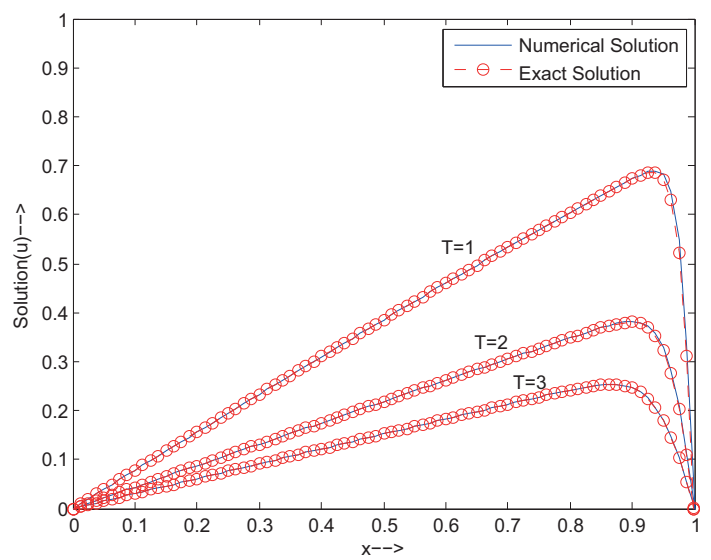

(b)

Fig. 4: Example 2: Numerical solutions at different times for $\Delta x=$ 0.0125 and different values of $v$ and $\Delta t$, (a) $v=0.02, \Delta t=0.0001$ (b) $v=0.01, \Delta t=0.001$.

In our first computation we have taken $v=0.02, \Delta x=$ $0.0125, \Delta t=0.001$ and compared the results obtained by proposed schemes with the exact solutions and reported in Table 11. In our next computation we took $n u=0.00667$ and the numerical results are tabulated in Table 12. From Tables 11 and 12 we infer that numerical solutions obtained

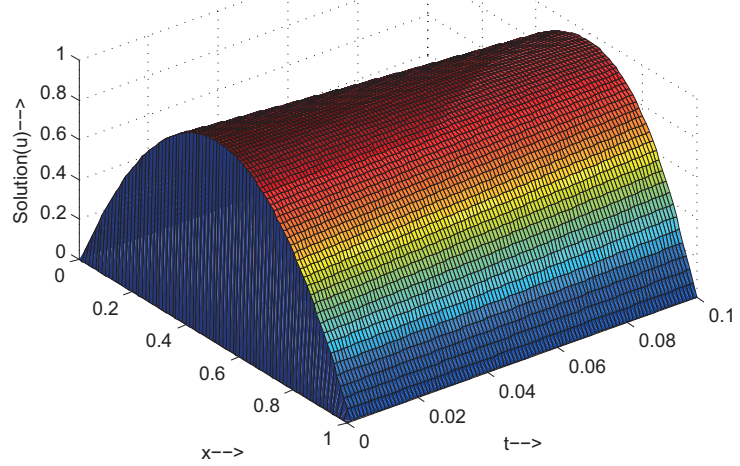

(a)

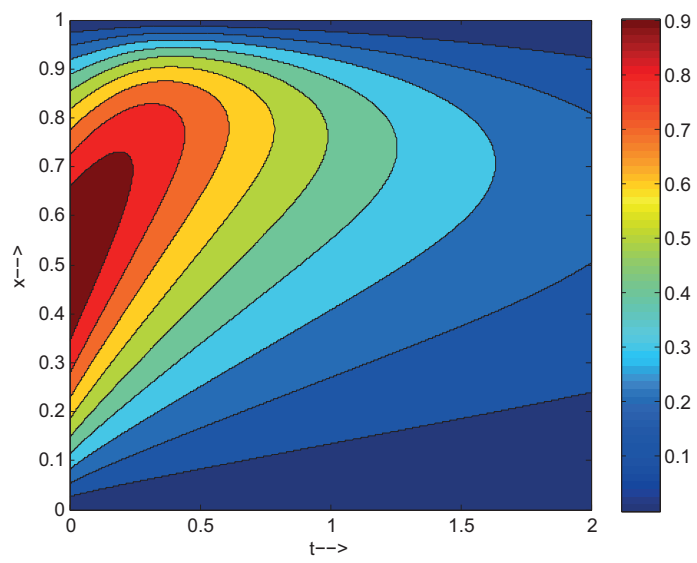

(b)

Fig. 5: Example 2: Physical behavior of numerical solutions at different times in 3D and contour for $\Delta x=0.0125, v=0.05, \Delta t=0.001$ (a) $T=0.1$ (b) $T=2$.

from BDF-2 and BDF-3 lies close to exact solutions. Next, we compared our numerical results with schemes given in Asaithambi [1] and Mittal and Jain [24] for $v=0.1,0.5$ and presented in Tables 13 and 14. Once again the proposed numerical schemes provide better accuracy than the schemes given in [1] and [24].

Example-4 In this test example, consider Burgers equation [25]

$$
u_{t}+u u_{x}=v u_{x x}, x \in[0,5] \text { and } t \in[0, T]
$$

with the boundary conditions

$$
u(0, t)=0=u(5, t), \quad 0 \leq t \leq T,
$$

and initial condition

$$
u(x, 0)= \begin{cases}\sin (\pi x), & 0<x<1 \\ -\frac{1}{2} \sin (\pi x), & 1 \leq x<2 \\ 0, & 2 \leq x<5\end{cases}
$$




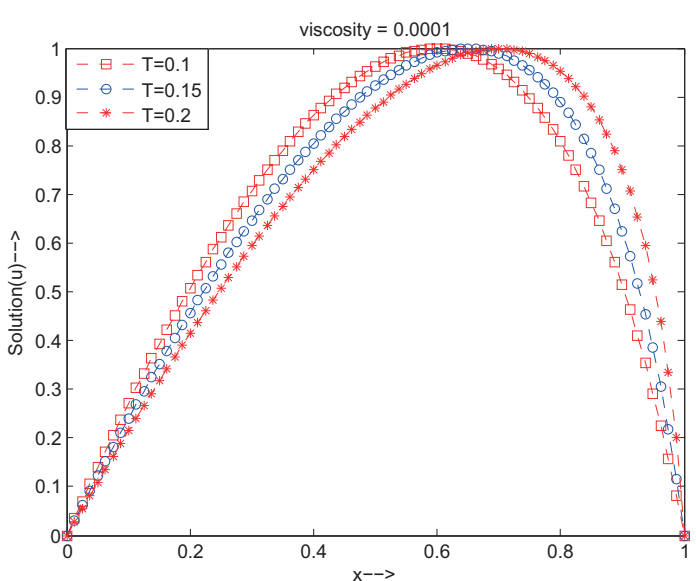

(a)

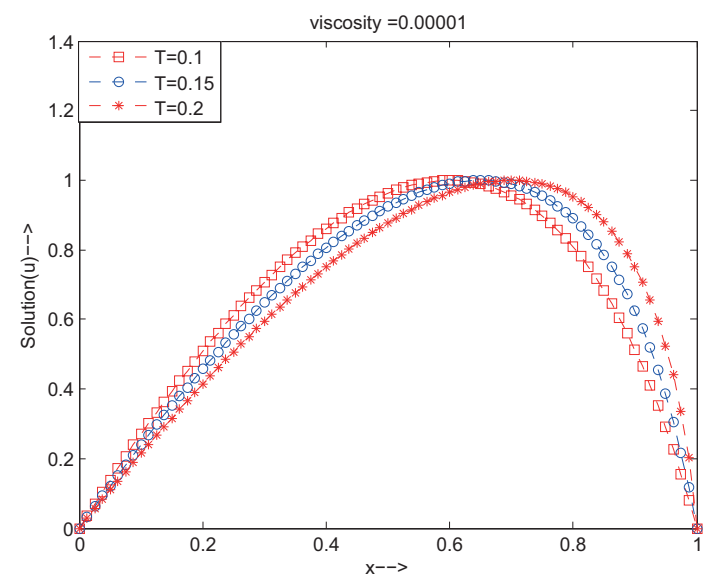

(b)

Fig. 6: Example 2: Physical behavior of numerical solutions at different times with $\Delta x=0.0125$ and $\Delta t=0.001$. (a) $v=0.0001$ (b) $v=0.00001$.

Table 11: Numerical solutions obtained by proposed schemes and the exact solutions for Example 3: $v=0.02, \Delta x=0.0125$ and $\Delta t=0.001$.

\begin{tabular}{cccccc}
\hline$T$ & $x$ & \multicolumn{3}{c}{ Computed Solution } & Exact Solution \\
\cline { 3 - 5 } & & BDF-1 & BDF-2 & BDF-3 & \\
\hline & 0.25 & $2.8267 \mathrm{E}-02$ & $2.8266 \mathrm{E}-02$ & $2.8266 \mathrm{E}-02$ & $2.8267 \mathrm{E}-02$ \\
1 & 0.50 & $5.1579 \mathrm{E}-02$ & $5.1578 \mathrm{E}-02$ & $5.1578 \mathrm{E}-02$ & $5.1577 \mathrm{E}-02$ \\
& 0.75 & $5.1393 \mathrm{E}-02$ & $5.1391 \mathrm{E}-02$ & $5.1391 \mathrm{E}-02$ & $5.1383 \mathrm{E}-02$ \\
\hline \multirow{2}{*}{2} & 0.25 & $2.4178 \mathrm{E}-02$ & $2.4178 \mathrm{E}-02$ & $2.4178 \mathrm{E}-02$ & $2.4177 \mathrm{E}-02$ \\
2 & 0.50 & $4.2343 \mathrm{E}-02$ & $4.2341 \mathrm{E}-02$ & $4.2341 \mathrm{E}-02$ & $4.2338 \mathrm{E}-02$ \\
& 0.75 & $3.9312 \mathrm{E}-02$ & $3.9309 \mathrm{E}-02$ & $3.9309 \mathrm{E}-02$ & $3.9300 \mathrm{E}-02$ \\
\hline & 0.25 & $2.0557 \mathrm{E}-02$ & $2.0556 \mathrm{E}-02$ & $2.0556 \mathrm{E}-02$ & $2.0555 \mathrm{E}-02$ \\
3 & 0.50 & $3.4760 \mathrm{E}-02$ & $3.4758 \mathrm{E}-02$ & $3.4758 \mathrm{E}-02$ & $3.4754 \mathrm{E}-02$ \\
& 0.75 & $3.0560 \mathrm{E}-02$ & $3.0557 \mathrm{E}-02$ & $3.0557 \mathrm{E}-02$ & $3.0549 \mathrm{E}-02$ \\
\hline
\end{tabular}

Table 12: Numerical solutions obtained by proposed schemes and the exact solutions for Example 3: $v=0.00667, \Delta x=0.0125$ and $\Delta t=0.001$.

\begin{tabular}{cccccc}
\hline \multirow{2}{*}{$T$} & \multirow{4}{*}{$x$} & \multicolumn{3}{c}{ Computed Solution } & \multirow{2}{*}{ Exact Solution } \\
\cline { 3 - 5 } & & BDF-1 & BDF-2 & BDF-3 & \\
\hline \multirow{2}{*}{1} & 0.25 & $1.04178 \mathrm{E}-02$ & $1.04178 \mathrm{E}-02$ & $1.04178 \mathrm{E}-02$ & $1.04178 \mathrm{E}-02$ \\
& 0.50 & $1.96104 \mathrm{E}-02$ & $1.96103 \mathrm{E}-02$ & $1.96103 \mathrm{E}-02$ & $1.96103 \mathrm{E}-02$ \\
& 0.75 & $2.07301 \mathrm{E}-02$ & $2.07300 \mathrm{E}-02$ & $2.07300 \mathrm{E}-02$ & $2.07285 \mathrm{E}-02$ \\
\hline \multirow{2}{*}{2} & 0.25 & $9.91134 \mathrm{E}-03$ & $9.91132 \mathrm{E}-03$ & $9.91132 \mathrm{E}-03$ & $9.91140 \mathrm{E}-03$ \\
& 0.50 & $1.83618 \mathrm{E}-02$ & $1.83618 \mathrm{E}-02$ & $1.83618 \mathrm{E}-02$ & $1.83615 \mathrm{E}-02$ \\
& 0.75 & $1.88182 \mathrm{E}-02$ & $1.88180 \mathrm{E}-02$ & $1.88180 \mathrm{E}-02$ & $1.88156 \mathrm{E}-02$ \\
\hline \multirow{3}{*}{3} & 0.25 & $9.42216 \mathrm{E}-03$ & $9.42213 \mathrm{E}-03$ & $9.42213 \mathrm{E}-03$ & $9.42222 \mathrm{E}-03$ \\
& 0.50 & $1.71928 \mathrm{E}-02$ & $1.71927 \mathrm{E}-02$ & $1.71927 \mathrm{E}-02$ & $1.71922 \mathrm{E}-02$ \\
& 0.75 & $1.71307 \mathrm{E}-02$ & $1.71304 \mathrm{E}-02$ & $1.71304 \mathrm{E}-02$ & $1.71275 \mathrm{E}-02$ \\
\hline
\end{tabular}

Table 13: Comparison with different numerical methods and exact solution of Example 3: $v=0.1, T=0.001, \Delta t=0.0001$.

\begin{tabular}{cccccc}
\hline$x$ & {$[24]$} & {$[1]$} & BDF-2 & BDF-3 & Exact Solution \\
\hline 0.1 & 0.065750 & 0.065750 & 0.065750 & 0.065750 & 0.065750 \\
0.2 & 0.131383 & 0.131383 & 0.131383 & 0.131383 & 0.131383 \\
0.3 & 0.196281 & 0.196281 & 0.196281 & 0.196281 & 0.196281 \\
0.4 & 0.258576 & 0.258576 & 0.258576 & 0.258576 & 0.258576 \\
0.5 & 0.313850 & 0.313850 & 0.313849 & 0.313849 & 0.313849 \\
0.6 & 0.352972 & 0.352972 & 0.352972 & 0.352972 & 0.352972 \\
0.7 & 0.359443 & 0.359444 & 0.359443 & 0.359443 & 0.359443 \\
0.8 & 0.309579 & 0.309583 & 0.309581 & 0.309581 & 0.309580 \\
0.9 & 0.184751 & 0.184756 & 0.184754 & 0.184754 & 0.184754 \\
\hline
\end{tabular}

putations we have considered viscosity, $v=0.1,0.01$, $\Delta t=0.001$ and $\Delta x=0.05$. In Figures 7 and 8 numerical solutions corresponding to $T \leq 5$ have been presented. Solution profiles indicate that the numerical solutions generated by proposed methods exhibit true physical behavior and is similar to those given in Mittal and Singhal [25] and Mittal and Jain [24].

Table 14: Comparison with different numerical methods and exact solution of Example 3: $v=0.5, T=0.001, \Delta t=0.0001$.

\begin{tabular}{cccccc}
\hline$x$ & {$[24]$} & {$[1]$} & BDF-2 & BDF-3 & Exact Solution \\
\hline 0.1 & 0.327870 & 0.327874 & 0.327869 & 0.327869 & 0.327870 \\
0.2 & 0.655071 & 0.655078 & 0.655069 & 0.655069 & 0.655069 \\
0.3 & 0.978416 & 0.978420 & 0.978413 & 0.978413 & 0.978413 \\
0.4 & 1.288469 & 1.288485 & 1.288464 & 1.288464 & 1.288464 \\
0.5 & 1.563074 & 1.563096 & 1.563065 & 1.563065 & 1.563064 \\
0.6 & 1.756654 & 1.756691 & 1.756645 & 1.756646 & 1.756642 \\
0.7 & 1.787204 & 1.787281 & 1.787214 & 1.787215 & 1.787206 \\
0.8 & 1.537649 & 1.537794 & 1.537707 & 1.537708 & 1.537694 \\
0.9 & 0.916786 & 0.916941 & 0.916871 & 0.916871 & 0.916860 \\
\hline
\end{tabular}

We have presented two dimensional figures to show the physical behavior of the above problem. In our com- 


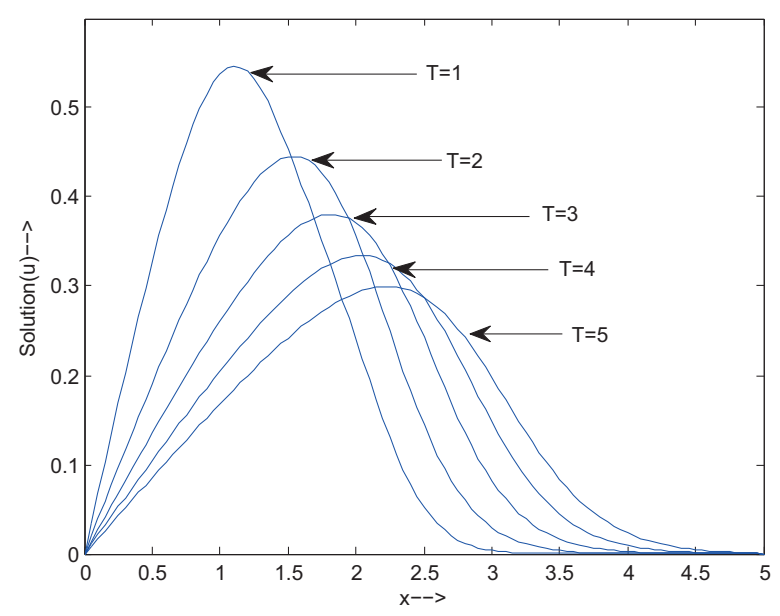

Fig. 7: Example 4: Solution profiles for $T \leq 5, v=0.1, \Delta t=0.001$ and $\Delta x=0.05$.

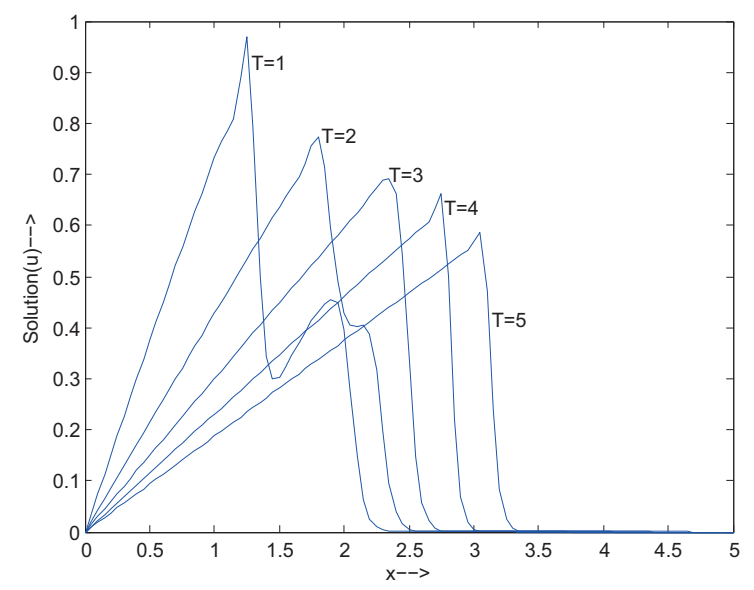

Fig. 8: Example 4: Solution profiles for $T \leq 5, v=0.01, \Delta t=0.001$ and $\Delta x=0.05$

\section{Conclusion}

In this paper, Burgers equation is solved by semidiscretization technique in combination with backward differentiation formulas. The proposed schemes are tested on four test problems and numerical solutions have been compared with exact solution. Numerical solutions shows excellent agreement with the exact solutions. It has been observed that numerical schemes with implicit solver BDF2 and BDF-3 provide better solutions than BDF-1. The proposed schemes are comparable with the scheme given in [15], [17] and it is better than the schemes given in [21], [32], [1] and [24]. Hence the proposed numerical schemes are efficient and reliable for solving the Burgers equation even for small value of viscosity parameter. Moreover, the scheme can be extended to solve other nonlinear problems like modified Burgers equation and Burgers equation in two dimension.

Acknowledgement: The authors are very thankful to the reviewers for their valuable comments and suggestions.

\section{References}

[1] Asai Asaithambi, Numerical solution of the Burgers' equation by automatic differentiation, Appl. Math. Comput. 216 (2010) 2700-2708.

[2] Ashish Awasthi, Deepa J S, An unconditionally stable numerical method for Burgers' equation, Proceedings of National Conference on Mathematics of Soft Computing, NIT Calicut, (2012) 21-27.

[3] Ashish Awasthi, Vijitha Mukundan, An unconditionally stable explicit method for Burgers' equation, Proceedings of National Conference on Recent Trends In Analysis and Applied Mathematics, NIT Trichy,(2013) 46-53.

[4] H. Bateman, Some recent researches in motion of fluids, Mon. Weather Rev.43, (1915) 163-170.

[5] A.R. Bahadir, Mustafa Sağlam, A mixed finite difference and boundary element approach to one-dimensional Burgers' equation, Appl. Math. Comput., 160 (2005) 663-673.

[6] J. M. Burgers, A mathematical model illustrating the theory of turbulence, Adv. Appl. Mech. 1 (1948) 171-199.

[7] J. M. Burgers, Mathematical examples illustrating relation occurring in the theory of turbulent fluid motion, Trans. Roy.Neth.Acad.Sci Amsterdam 17 (1939) 1-53.

[8] J. D Cole, On a quasi-linear parabolic equation occurring in aerodynamics, Quart. Appl. Math 9 (1951) 225-236.

[9] D. J. Evans and A. R. Abdullah, The Group explicit Method for the Solution of Burgers' equation, Computing 32 (1984) 239253.

[10] Feng Gao, Chunmei Chi, Numerical solution of nonlinear Burgers' equation using high accuracy multi-quadric quasiinterpolation, Appl. Math. Comput. 229 (2014) 414-421.

[11] Yun Gao, Li-Hua Le, Bao-Chang Shi, Numerical solution of Burgers' equation by lattice Boltzmann method, Appl. Math. Comput. 219 (2013) 7685-7692.

[12] B. M. Herbst, S. W. Schoombie, D. F Griffiths, A. R Mitchell, Generalized Petro-Galerkin Method for the numerical solution of Burgers' equation, Int J. Numer. Methods Eng. 20 (1984) 1273-1289.

[13] B. Hosseini, R. Hashemi, Solution of Burgers' equation using a local-RBF meshless method, Int. J. Comput. Methods Eng. Sci. Mech. 12 (2011) 44-58.

[14] Ziwu Jiang, Renhong Wang, An improved numerical solution of Burgers' equation by cubic B-spline quasi-interpolation, J. Inform. Comput. Sci. 7 (5) (2010) 1013-1021.

[15] Ram Jiwari, A Haar wavelet quasilinearization approach for numerical simulation of Burgers' equation, Computer Physics Communications 183 (2012) 2413-2423.

[16] Mohan. K. Kadalbajoo, A. Awasthi, A numerical method based on Crank-Nicolson scheme for Burgers' equation, Appl. Math. 
Comput. 182 (2006) 1430-1442.

[17] Mohan. K. Kadalbajoo, K.K Sharma, A. Awasthi, A parameteruniform implicit difference scheme for solving time-dependent Burgers' equation, Appl. Math. Comput. 170 (2005) 1365-1393.

[18] R. Kuhne, N Gartner, C. Messner and A.R. (Eds.), Transportation Research Board (TRB) Special Report, Traffic Flow Theory 165 (1998).

[19] L.A Kurtz, R.E Smith, C.L Parks and L.R Boney, A comparison of the method of lines to finite difference techniques in solving time-dependent partial differential equations, Computers and Fluids, 6 (1977) 49-70.

[20] S. Kutluay, A. R. Bahadir, A. Ozdes, Numerical solution of the one-dimensional Burgers' equation: explicit and exact explicit finite difference methods, J. Comput. Appl. Math. 103 (1999) 251-261.

[21] S. Kutluay, A. Esen, I. Dag, Numerical solutions of the Burgers' equation by the least-squares quadratic B-spline finite element method, J. Comput. Appl. Math. 167 (2004) 21-33.

[22] Wenyuan Liao, An implicit fourth-order compact finite difference scheme for one-dimensional Burgers' equation, Appl. Math. Comput. 206 (2008) 755-764.

[23] Kaysar Rahman, Nurmamat Helil, Rahmatjan Yimin, Some New Semi-Implicit Finite Difference Schemes for Numerical Solution of Burgers' Equation, International Conference on Computer Application and System Modeling (ICCASM 2010), 978-1-4244-7237-6/10 20l0 IEEE V14-451.

[24] R. C. Mittal, R. K. Jain, Numerical solutions of nonlinear Burgers' equation with modified cubic B-splines collocation method, Appl. Math. Comput. 218 (2012) 7839-7855.

[25] R. C. Mittal, P. Singhal, Numerical solutions of Burgers' equation, Commun. Numer. Methods Eng.9 (1993) 397-406.

[26] Vijitha Mukundan, Ashish Awasthi, Numerical implementation of BDF-2 via method of lines for time dependent nonlinear Burgers' equation, International Journal of Scientific and Engineering Research, Volume 5, Issue 9, September-2014, ISSN 2229-5518.

[27] Vijitha Mukundan, Ashish Awasthi, Efficient numerical techniques for Burgers' equation, Appl. Math. Comput. 262(2015) 282-297.

[28] Vijitha Mukundan, Ashish Awasthi, A higher order numerical implicit method for non-linear Burgers' equation, Differ. Equ. Dyn. Syst., 25(2) (2017) 169-186.
[29] Vijitha Mukundan, Ashish Awasthi, Linearized implicit numerical method for Burgers' equation, Nonlinear Engineering Modelling and Applications, De Gruyter, 5(4) (2016) 219-234.

[30] M. M Rashidi, D.D Ganji, S. Dinarvand, Explicit Analytical Solutions of the Generalized Burger and Burger-Fisher Equations by Homotopy Perturbation Method, Numer. Methods Partial Differ. Equ. 25 (2) (2009) 409-417.

[31] M. M Rashidi, G. Domairry, S. Dinarvand, Approximate Solutions for the Burger and Regularized Long Wave Equations by Means of the Homotopy Analysis Method, Commun. Nonlinear Sci. Numer. Simul. 14 (3) (2009) 708-717.

[32] T. Özis, E. N. Aksan, A. Ozdes, A finite element approach for solution of Burgers' equation, Appl. Math. Comput. 139(2003) 417-428.

[33] K. Pandey, L. Verma, A. K. Verma, On a finite difference scheme for Burgers' equation, Appl. Math. Comput. 215 (2009) 2206-2214

[34] D.E Panayotounakos and D. Drikakis, On the closed form solutions of the wave, diffusion and Burgers' equation in fluid mechanics, ZAMM Z. angew Math. Mech., 75 (1995) 437-447.

[35] L.G. Reyna and M.J. Ward, On the exponentially slow motion of a viscous shock, Commun. on Pure and Applied Mathematics, XLVIII (1995) 79-120.

[36] Long Shao, Xinlong Feng, Yinnian He, The local discontinuous Galerkin finite element method for Burgers' equation, Math. and Computer Modeling 54 (2011) 2943-2954.

[37] E. Varöglu, W. D. LiamFinn, Space time finite elements incorporating characteristics for the Burgers' equation, Int. J. Numer. Methods Eng. 16 (1980) 171-184.

[38] M. Vergassola, B. Durbrulle, U. Frisch and A. Nullez, Burgers' equation, devil's staircase and mass distribution for largescale structures, Astronom. and Astrophys., 289 (1994) 325 356.

[39] W. L. Wood, An exact solution for Burgers' equation, Commun Numer. Methods Eng. 22 (2006), 797-798.

[40] Huantian Xie, Dingfang Li, A meshless method for Burgers' equation using MQ-RBF and high-order temporal approximation, Appl. Math. Modelling 37 (2013) 9215-9222.

[41] Pei-Guang Zhang, Jian-Ping Wang, A predictor-corrector compact finite difference scheme for Burgers' equation, Appl. Math. Comput. 219 (2012) 892-898. 